\title{
Determination of isovitexin from Lespedeza cuneata using a validated HPLC-UV method
}

\author{
Ju Sung Lee ${ }^{1} \cdot$ Leo Adrianne Paje ${ }^{1} \cdot$ Sang-Woo Yoo $^{2} \cdot$ Seong Lee $^{3} \cdot$ Ja-Jung Ku$^{4}$ \\ - Sanghyun Lee ${ }^{1}$ iD
}

Received: 7 October 2020 / Accepted: 18 January 2021 / Published Online: 31 March 2021

(C) The Korean Society for Applied Biological Chemistry 2021

\begin{abstract}
Isovitexin, a marker compound with various pharmacological activities, in Lespedeza cuneata, was analyzed using high performance liquid chromatography coupled with UV (HPLC/UV). There are no previous reports on using L. cuneata as the source material for the quantification of isovitexin. In this study, we developed an optimized method using HPLC-UV analysis, which was validated using various parameters. Our method demonstrated high specificity, and good separation of the chromatographic peak was achieved. Parameters such as linearity $\left(r^{2} \geq 0.9997\right)$, precision, and accuracy indicated that our proposed analytical method had good reliability and sensitivity. These results demonstrate the utility and convenience of our method for rapidly quantifying isovitexin in $L$. cuneata extracts.
\end{abstract}

Keywords High-performance liquid chromatography Isovitexin $\cdot$ Lespedeza cuneata $\cdot$ Method validation

J. S. Lee and L. A. Paje equally contributed to this article.

Sanghyun Lee $(\square)$

E-mail:slee@cau.ac.kr

${ }^{1}$ Department of Plant Science and Technology, Chung-Ang University, Anseong 17546, Republic of Korea

${ }^{2}$ Research \& Development Center, Natural Way Co., Ltd., Pocheon 11160, Republic of Korea

${ }^{3}$ Dankook University Hospital Research Institute of Clinical Medicine, Cheonan 31116, Republic of Korea

${ }^{4}$ Forest Bioinformation Division, National Institute of Forest Science, Suwon 16631, Republic of Korea

This is an Open Access article distributed under the terms of the Creative Commons Attribution Non-Commercial License (http://creativecommons. org/licenses/by-nc/3.0/) which permits unrestricted non-commercial use, distribution, and reproduction in any medium, provided the original work is properly cited.

\section{Introduction}

Lespedeza cuneata (LC), a well-known traditional medicine, is an aggressive warm-season perennial legume belonging to the Fabaceae family. The native distribution of LC ranges from temperate to tropical regions of Asia. It has been introduced to other countries for use as forage on poor soils, hay production, and controlling erosion along roadsides [1]. Aerial parts of LC have been traditionally used to protect the kidney, liver, and lung in traditional Asian medicine [2]. Our previous study showed that LC could suppress cancer cell proliferation via apoptosis induction [3]. Phytochemical investigations of LC led to the isolation of tannins, $\beta$-sitosterol, pinitol, flavonoids, lignans and their glycosides. The flavonoids include vitexin, myricitrin, rutin, $C$-glycosyl flavones such as isovitexin, vicenin II, isoorientin, desmodin, lucenin II, and homoadonivernith, and $O$-glycosyl flavonols such as trifolin, hyperin, avicularin, juglanin, and hirsutrin [4,5].

Compounds derived from natural products have been shown to possess pharmacological activities useful for treating different types of diseases. They may act as the active components for traditional medicines and modern medicines [6,7]. Among these are flavonoids, a large group of naturally occurring substances with diverse structures [8,9]. They are considered major bioactive compounds and are known for their potential health benefits, such as anti-viral effects, and in treating cancer, as well as cardiovascular, and neurodegenerative disorders [10]. Flavonoids have various other biological activities such as protecting DNA damage, and the skin from UV light exposure, exerting antiseptic and antiinflammatory effects, strengthening capillaries, and softening, soothing, moistening the skin. Based on these properties, flavonoids can be useful as ingredients in the production of pharmaceutical and cosmetic products [11,12]. This study has been focused on LC's flavonoid content, particularly isovetixin, which is reported to be pharmacologically active.

Isovitexin (apigenin 6- $C$-glucoside) is an isomer of vitexin. Isovitexin has been proven to possess various activities, such as 
anti-inflammatory, anti-oxidant, and anti-AD effects, and could be used as a novel therapeutic approach for treating diabetic complications [13-16]. Our recent study reported that isovitexin from LC showed effective antioxidant activity via scavenging $\mathrm{OH}$ radicals [17]. Some studies have indicated that isovitexin can be used as a novel therapeutic approach to treating cognitive deficits [18]. LC also offers a potential therapeutic approach for preventing pathogenic or diabetic complications [19]. These findings suggest that isovitexin is a marker compound that possesses various biological activities.

Considering the beneficial effects of LC is attributed to its phytochemical constituents, this study's objective was to develop a validated analytical method for the quantitative analysis of isovitexin. This analysis is an integral part of the source material's quality control, which will guarantee the efficient determination of the marker compound [20]. This is the first study, to the best of our knowledge, to establish a validated analytical method using HPLC/UV. Validation was achieved by assessing specific parameters such as specificity, accuracy, linearity, limit of detection (LOD), limit of quantification (LOQ), and precision.

\section{Materials and Methods}

\section{Plant Materials}

The dried aerial parts of LC were collected from Inje, Gangwon Province by the Research \& Development Center, Natural Way Co., Ltd., Pocheon, Korea. Voucher specimens were deposited at the Department of Plant Science and Technology, Chung-Ang University, Anseong, Korea.

\section{Instrumentation and Chemicals}

The analyses were performed using an HPLC system (Agilent series 1260), which consisted of a quaternary pump equipped with a UV detector (Milford, MA, USA). All samples were separated using an INNO $\mathrm{C}_{18}$ column $(4.6 \times 250 \mathrm{~mm}, 5 \mu \mathrm{m})$. HPLC-grade acetonitrile, water, and glacial acetic acid were purchased from J.T. Baker (Avantor, Radnor, PA, USA). The reference compound isovitexin (Fig. 1) was purchased from Natural Product Institute of Science and Technology (Anseong, Korea).

\section{Preparation of Sample and Standard Solutions}

To obtain a test solution, $20 \mathrm{mg}$ of LC extract (LCE) from Research \& Development Center, Natural Way Co., Ltd. (Pocheon, Korea) was dissolved in $1 \mathrm{~mL}$ methanol (MeOH). Standard stock solutions were prepared by weighing $1 \mathrm{mg}$ of isovitexin and dissolving in $1 \mathrm{~mL}$ of $\mathrm{MeOH}$. The working solutions were prepared by serial dilution to obtain a calibration curve.

\section{HPLC-UV Chromatographic Conditions}

A gradient elution system composed of $0.5 \%$ acetic acid in water<smiles>O=c1cc(-c2ccc(O)cc2)oc2cc(O)c([C@@H]3O[C@H](CO)[C@@H](O)[C@H](O)[C@H]3O)c(O)c12</smiles>

Fig. 1 Chemical structure of isovitexin

(A) and acetonitrile (B) was used for the chromatographic conditions. The gradient elution program started with the mobile phase (A) at $90 \%$ and was decreased to $83 \%$ after 5 min. Solvent A was further reduced to $81 \%$ after $15 \mathrm{~min}$ and was maintained until $30 \mathrm{~min}$. It was increased from 81 to $91 \%$ at $31 \mathrm{~min}$ and maintained until $35 \mathrm{~min}$. The flow rate of the mobile phase was $1 \mathrm{~mL} / \mathrm{min}$ and the injection volume was $10 \mu \mathrm{L}$. The UV detection wavelength was $270 \mathrm{~nm}$ and the temperature of the column was maintained at $30^{\circ} \mathrm{C}$.

\section{HPLC Method Validation}

The analytical method used to determine isovitexin in LCE was validated by assessing different parameters such as specificity, linearity, accuracy, precision, LOD and LOQ. Specificity was tested to determine whether the separation method was free from any potential interference or impurities of the analytes. Linearity between the peak area and the concentration was analyzed using five concentrations of standard mixtures $(0.25-0.015 \mathrm{mg} / \mathrm{mL})$ with three repeated injections. A calibration curve was plotted using the peak areas measured at $270 \mathrm{~nm}$ on the chromatogram against the standard solutions' known concentration. Accuracy was assessed utilizing recovery assays by adding the reference compound isovitexin to the sample at three different sample concentrations. The measurements were obtained five times, and the \% recovery was calculated. The precision of the method was investigated in terms of its intra- and inter-day variations. Intra-day precision was measured by obtaining five injections of each sample in one day. Inter-day precision was measured using the same method in a different laboratory to compare the reproducibility between the values obtained. LOD and LOQ were determined as the lowest concentration producing an appropriate peak shape and experimentally calculated by injecting a series of diluted solutions with known concentrations until the signal-to-noise ratio was 3:1 for LOD and 10:1 for LOQ.

\section{Calibration Curve}

Five different isovitexin concentrations ranging from 0.25-0.015 $\mathrm{mg} / \mathrm{mL}$ were prepared by serially diluting the standard stock solutions. The calibration curve was calculated by plotting the peak area $(\mathrm{Y})$ against the concentration $(\mathrm{X}, \mathrm{mg} / \mathrm{mL})$. The analyte 
(A)

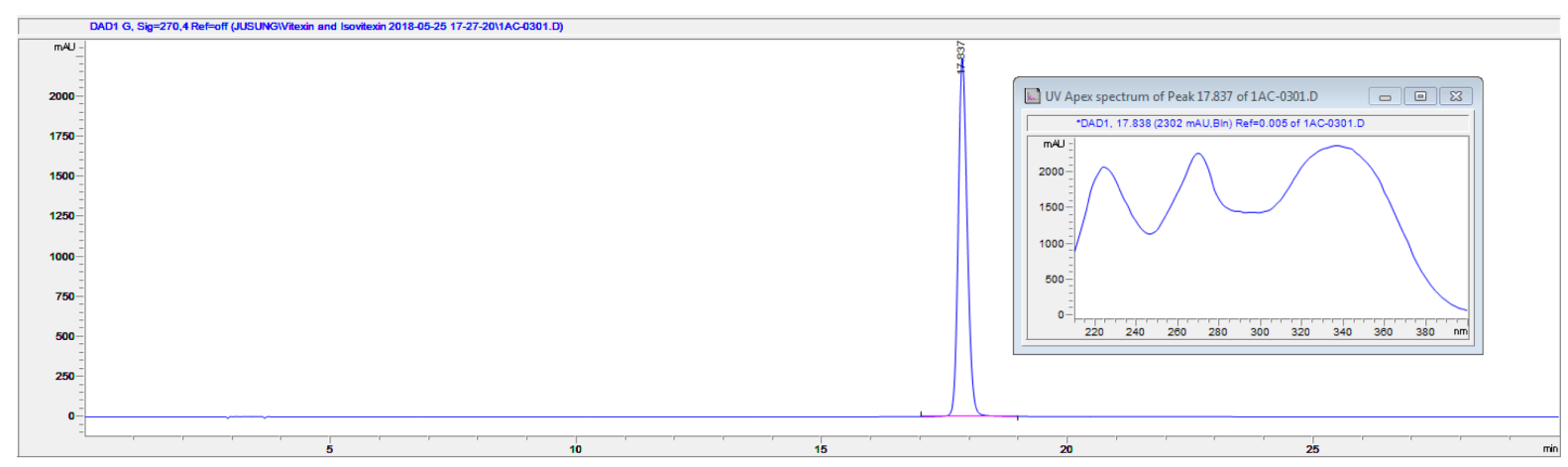

(B)

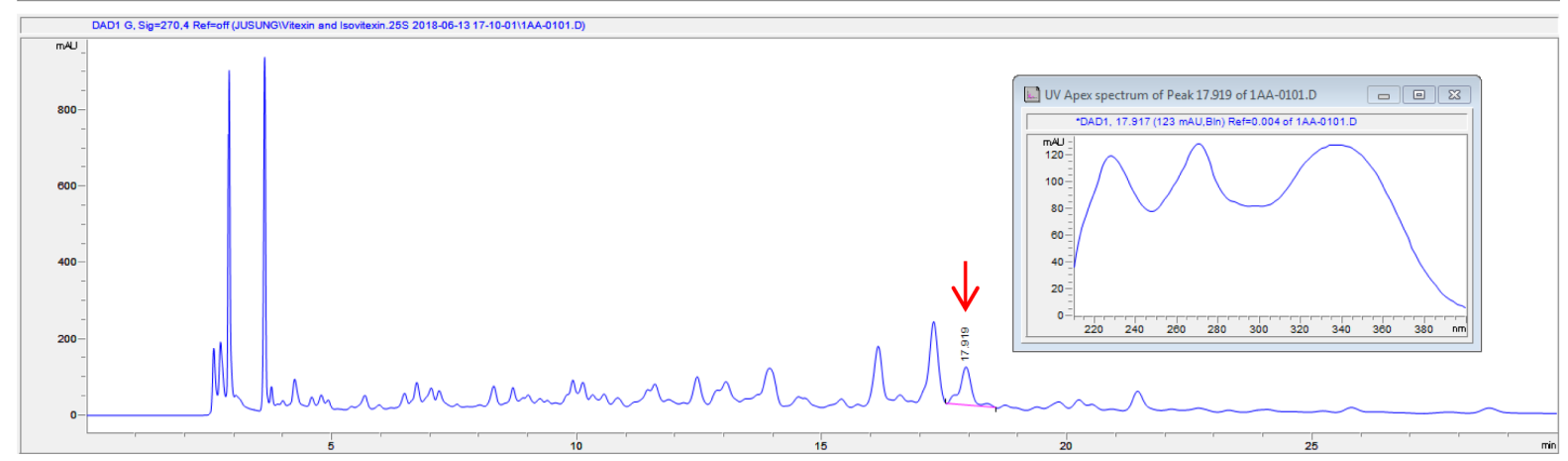

Fig. 2 HPLC chromatograms and UV spectra of isovitexin (A) and LCE (B)

concentrations in the samples were calculated using the calibration equation. All values are reported as the mean $(n=3) \pm$ standard deviation.

\section{Results and Discussions}

Analytical studies regarding the quantification of isovitexin from other plant sources such as buckwheat sprouts have already been established [21]. This compound was also found and analyzed in plants such as Passiflora, pigeon pea, wheat leaves, mimosa, bamboo; it was also screened as a bioactive integrant [13,22-27]. The analytical method we employed in this study aimed to develop reasonably convenient chromatographic conditions capable of separating and quantifying the flavone isovitexin present in LCE. The method was validated using different parameters to confirm its effectiveness in quantifying the compound.

The method's specificity was tested by analyzing and comparing the chromatograms of the standard compound and the test solution. Figure 2 shows the chromatograms of the standard and the LC extract. The retention time of isovitexin was recorded at $17.8 \mathrm{~min}$. The chromatogram in Fig. 2B depicts an efficient separation of the isovitexin peak found in LCE. The results suggest the method's high specificity, as no impurity peaks were detected close to its retention time. The wavelength that provided a good response in detecting all impurities and the reference compound in a single run was $270 \mathrm{~nm}$.

Linearity was evaluated by plotting the peak area versus the standard compound's concentration expressed as $\mathrm{mg} / \mathrm{mL}$. The correlation coefficient $r$ value for isovitexin was 0.9997 which indicates a strong linear relationship between the peak area and the compound concentration (Table 1). The LOQ value represents the lowest concentration of the analyzed compounds quantifiable with acceptable precision and accuracy by the instrument and the analytical method while LOD is defined as the lowest analyte quantity that renders a measurable signal that is three times greater than the noise level. As shown in Table 1, the LOD and LOQ wereas measured to be 0.027 and $0.084 \mathrm{mg} / \mathrm{mL}$, respectively. This finding indicates that our analytical method exhibited good sensitivity, as the values were within the acceptable limits.

LCE was spiked with known concentrations of isovitexin to measure the accuracy of the method. The recovery of each substance was obtained by calculating the amount quantified and the original amount. The analyses were performed 5 times. The results in Table 2 show that the obtained recovery rates ranged from $96.42-101.3 \%$. These values conform to the acceptable range, suggesting our method was highly accurate. The method's precision was assessed using both intra- and inter-day precision analyses of isovitexin. As displayed in Table 3, the coefficient of variation ranged from 0.20 to $0.81 \%$. The values obtained were less than $2 \%$ indicating that our proposed analytical method was reliable and satisfactory.

Characterization of the chemical composition of medicinal plants helps identify potential compounds responsible for biological activities. In line with this, it is crucial to develop a validated analytical technique to standardize compounds present in plant 
Table 1 Linearity, limit of detection (LOD), and limit of quantification (LOQ) for isovitexin

\begin{tabular}{|c|c|c|c|c|c|c|c|c|c|}
\hline \multicolumn{2}{|c|}{ Compound } & \multicolumn{2}{|l|}{ Range $(\mathrm{mg} / \mathrm{mL})$} & \multicolumn{2}{|c|}{ Calibration equation $^{a}$} & $r^{2 b}$ & $\mathrm{LOD}(\mathrm{mg} / \mathrm{mL})$ & \multicolumn{2}{|c|}{ LOQ $(\mathrm{mg} / \mathrm{mL})$} \\
\hline \multicolumn{2}{|c|}{ Isovitexin } & $0.25-0.015$ & & \multicolumn{2}{|c|}{$Y=24.052 X+6.7764$} & 0.9997 & \multicolumn{2}{|l|}{0.0279} & 0.0846 \\
\hline \multicolumn{10}{|c|}{$\begin{array}{l}{ }^{a} \mathrm{Y}=\text { peak area, } \mathrm{X}=\text { concentration of standards }(\mathrm{mg} / \mathrm{mL}) \\
{ }^{b} r^{2}=\text { correlation coefficient for the five data points in the calibration }(\mathrm{n}=5)\end{array}$} \\
\hline \multicolumn{10}{|c|}{ Table 2 Accuracy determination for isovitexin } \\
\hline \multirow{2}{*}{ Compound } & \multirow{2}{*}{$\begin{array}{l}\text { Concentration } \\
(\mathrm{mg} / \mathrm{mL})\end{array}$} & \multicolumn{5}{|c|}{ Found content $(\%)$} & \multirow{2}{*}{ RSD (\%) } & \multirow{2}{*}{$\begin{array}{l}\text { Overall } \\
\text { Recovery } \\
(\%)\end{array}$} & \multirow{2}{*}{$\begin{array}{l}\text { Recovery rate } \\
(\%)\end{array}$} \\
\hline & & $1^{\text {st }}$ & $2^{\text {nd }}$ & $3^{\text {rd }}$ & $4^{\text {th }}$ & $5^{\text {th }}$ & & & \\
\hline \multirow{3}{*}{ Isovitexin } & 0.025 & 96.5 & 96.5 & 96.5 & 96.1 & 96.5 & 0.60 & \multirow{3}{*}{98.18} & \multirow{3}{*}{$96.42-101.3$} \\
\hline & 0.0125 & 101.4 & 101.0 & 101.4 & 101.5 & 101.2 & 0.20 & & \\
\hline & 0.00625 & 96.6 & 96.9 & 96.4 & 96.4 & 97.8 & 0.19 & & \\
\hline
\end{tabular}

Table 3 Intra- and inter-day precision of isovitexin

\begin{tabular}{|c|c|c|c|c|c|c|c|c|}
\hline \multirow[b]{2}{*}{ Compound } & \multicolumn{4}{|c|}{ Intra-day $(n=5)$} & \multicolumn{4}{|c|}{ Inter-day $(n=5)$} \\
\hline & $\begin{array}{c}\text { Spiked } \\
\text { concentration } \\
(\mathrm{mg} / \mathrm{g})\end{array}$ & $\begin{array}{c}\text { Found } \\
\text { concentration } \\
(\mathrm{mg} / \mathrm{g})\end{array}$ & $\begin{array}{c}\text { RSD } \\
(\%)\end{array}$ & $\begin{array}{c}\text { Recovery } \\
(\%)\end{array}$ & Repetition & $\begin{array}{c}\text { Found } \\
\text { concentration } \\
(\mathrm{mg} / \mathrm{g})\end{array}$ & $\begin{array}{c}\text { RSD } \\
(\%)\end{array}$ & $\begin{array}{c}\text { Recovery } \\
(\%)\end{array}$ \\
\hline \multirow{3}{*}{ Isovitexin } & 5.0 & 0.49 & 0.81 & 100 & A & 0.50 & 1.19 & 102 \\
\hline & 7.5 & 0.49 & 0.20 & 100 & $\mathrm{~B}$ & 0.50 & 0.10 & 102 \\
\hline & 10.0 & 0.49 & 0.40 & 100 & $\mathrm{C}$ & 0.50 & 0.98 & 102 \\
\hline
\end{tabular}

extracts. In this study, we developed an optimized and reliable HPLC-UV analytical method for quantifying isovitexin in LC extracts. This compound has been reported to possess many pharmacological activities. Our previous study showed that the antioxidant properties of LCE could be attributed to the presence of isovitexin [17].

Isovitexin was successfully determined using HPLC-UV. The quantification results of LC extract found the concentration of isovitexin to be $0.494 \mathrm{mg} / \mathrm{g}$. The validation of our method delivered excellent results in terms of specificity, accuracy, precision, and linearity. This finding supports the use of our method for accurately identifying the marker compound in LCE. The results of our study could be used as a basis for promoting a standardized method for content determination in large-scale extraction processes and industrialization of its extracts for pharmaceutical purposes.

Acknowledgments This work was supported by the Korea Institute of Planning and Evaluation for Technology in Food, Agriculture, Forestry, and Fisheries (iPET) through the Technology Commercialization Support Program funded by the Ministry of Agriculture, Food, and Rural Affairs (MAFRA) (816004-02-1-SB010), Korea and the Korea Health Technology R\&D Project, through the Korea Health Industry Development Institute (KHIDI) funded by the Ministry of Health \& Welfare (HP20C0226), Republic of Korea.

\section{References}

1. Wang C, Zhou B, Palm HL (2008) Detecting invasive Sericea Lespedeza (Lespedeza cuneata) in Mid-Missouri Pastureland using hyperspectral imagery. Environ Manag 41: 853-862

2. Kwon DJ, Kim JK, Ham YH, Bae YS (2007) Flavone glycosides from the aerial parts of Lespedeza cuneata. J Korean Soc Appl Biol Chem 50: 344-347

3. Baek J, Lee D, Lee TK, Song JH, Lee JS, Lee S, Yoo SW, Ki SK, Moon E, Lee S, Kim KH (2018) (-)-9'-O-( $\alpha$-L-Rhamnopyranosyl)lyoniresinol from Lespedeza cuneata suppresses ovarian cancer cell proliferation through induction of apoptosis. Bioorg Med Chem Lett 28: 122-128

4. Baek J, Lee TK, Song JH, Choi E, Ko HJ, Lee S, Choi SU, Lee S, Yoo SW, Kim SH, Kim KH (2018) Lignan glycosides and flavonoid glycosides from the aerial portion of Lespedeza cuneata and their biological evaluations. Molecules 23: 1920

5. Yoo G, Park SJ, Lee TH, Yang H, Baek YS, Kim N, Kim YJ, Kim SH (2015) Flavonoids isolated from Lespedeza cuneata G. Don and their inhibitory effects on nitric oxide production in lipopolysaccharidestimulated BV-2 microglia cells. Pharmacogn Mag 11: 651-656

6. Sean KM (2012) Natural products research. Nat Prod Chem Res 1: e101

7. Woldeyes S, Adane L, Tariku Y, Muleta D, Begashaw T (2012) Evaluation of antibacterial activities of compounds isolated from Sida rhombifolia Linn. (Malvaceae). Nat Prod Chem Res 1: 101

8. Stalikas CD (2007) Extraction, separation, and detection methods for phenolic acids and flavonoids. J Sep Sci 30: 3268-3295

9. Koes RE, Quattrocchio F (1994) The flavonoid biosynthetic pathway in plants: Function and evolution. BioEssays 16: 123-132

10. Benavente-García O, Castillo J, Marin FR, Ortuño A, Del Río JA (1997) Uses and properties of citrus flavonoids. J Agric Food Chem 45: 45054515

11. Chuarienthong P, Lourith N, Leelapornpisid P (2010) Clinical efficacy comparison of anti-wrinkle cosmetics containing herbal flavonoids. Int J Cosm Sci 32: 99-106

12. Malinowska $P$ (2013) Effect of flavonoids content on antioxidant activity of commercial cosmetic plant extracts. Herba Polonica 59: 63-75

13. Zhang J, Yuan K, Zhou WL, Zhou J, Yang P (2011) Studies on the active components and antioxidant activities of the extracts of Mimosa pudica Linn. from southern China. Pharmacogn Mag 7: 35-39 
14. Huang ST, Chen CT, Chieng KT, Huang SH, Chiang BH, Wang LF, Kuo HS, Lin CM (2005) Inhibitory effects of a rice hull constituent on tumor necrosis factor alpha, prostaglandin E2, and cyclooxygenase-2 production in lipopolysaccharide-activated mouse macrophages. Ann N Y Acad Sci 1042: 387-395

15. Lin CM, Huang ST, Liang YC, Lin MS, Shih CM, Chang YC, Chen TY, Chen CT (2005) Isovitexin suppresses lipopolysaccharide-mediated inducible nitric oxide synthase through inhibition of NF-kappa B in mouse macrophages. Planta Med 71: 748-753

16. Choi JS, Islam MN, Ali MY, Kim EJ, Kim YM, Jung HA (2014) Effects of $C$-glycosylation on anti-diabetic, anti-Alzheimer's disease and antiinflammatory potential of apigenin. Food Chem Toxicol 64: 27-33

17. Lee J, Lee AY, Quilantang N, Geraldino PJ, Cho E, Lee S (2019) Antioxidant activity of avicularin and isovitexin from Lespedeza cuneata. J Appl Biol Chem 62: 143-147

18. de Oliveira DR, Zamberlam CR, Gaiardo RB, Rego GM, Cerutti JM, Cavalheiro AJ, Cerutti SM (2014) Flavones from Erythrina falcata are modulators of fear memory BMC Complement. Altern Med 14: 288-301

19. Peng XF, Zheng ZP, Cheng KW, Shan F, Ren GX, Chen F, Wang MF (2008) Inhibitory effect of mung bean extract and its constituents vitexin and isovitexin on the formation of advanced glycation end products Food Chem 106: 475-481

20. Landim LP, Feitoza GS, Costa JGM (2012) Development and validation of a HPLC method for the quantification of three flavonoids in a crude extract of Dimorphandra gardneriana. Braz J Pharmacogn 23: 58-64
21. Jang D, Jung YS, Kim MS, Oh SE, Nam TG, Kim DO (2019) Developing and validating a method for separating flavonoid isomers in common buckwheat sprouts using HPLC-PDA. Foods 8: 549

22. Fu Y, Zu Y, Liu W, Hou C, Chen L, Li S, Shi X, Tong M (2007) Preparative separation of vitexin and isovitexin from pigeonpea extracts with macroporous resins. J Chromatogr A 1139: 206-213

23. Fu YJ, Zu YG, Liu W, Zhang L, Tong MH, Efferth T, Kong Y, Hou CL, Chen LY (2008) Determination of vitexin and isovitexin in pigeonpea using ultrasonic extraction followed by LC-MS. J Sep Sci 31: 268-275

24. Zucolotto SM, Fagundes C, Reginatto FH, Ramos FA, Castellanos L, Duque C, Schenkel EP (2012) Analysis of $C$-glycosyl flavonoids from South American Passiflora species by HPLC-DAD and HPLC-MS. Phytochem Anal 23: 232-239

25. Close CA, Pereira JH, Yariwake M (2005) Distinction of the $C$ glycosylflavone isomer pairs orientin/isoorientin and vitexin/isovitexin using HPLC-MS exact mass measurement and in-source CID. Phytochem Anal 16: 295-301

26. Wang J, Tang F, Yue Y, Guo X, Yao X (2010) Development and validation of an HPTLC method for simultaneous quantitation of isoorientin, isovitexin, orientin, and vitexin in bamboo-leaf flavonoids. J AOAC Int 93: 1376-1383

27. Moheb A, Ibrahim RK, Roy R, Sarhan F (2011) Changes in wheat leaf phenolome in response to cold acclimation. Phytochemistry 72: 2294 2307 